\title{
Integração Ensino-Pesquisa na Educação Médica: Perfil Docente de um Colegiado
}

\section{Teaching-Research Integration in Medical Education: Teaching Staff Profile of a College}

Pedro Mansueto Melo Souza Camila Almada Nunes

Clarice Santiago Silveira Silvia Maria Nóbrega-Therrien ${ }^{l}$

\section{PALAVRAS-CHAVE}

- Educação Médica.

- Docentes Médicos.

- Pesquisadores.

- Currículo.

\section{KEYWORDS}

- Education, Medical.

- Faculty, Medical.

- Research Personnel.

- Curriculum

Recebido em: 19/07/2011

Aprovado em: 11/10/2011

REVISTA BRASILEIRA DE EDUCAÇÃO MÉDICA

\section{RESUMO}

A formação em pesquisa é um elemento importante para o preparo de médicos com perfil crítico-reflexivo. Tendo o docente como pesquisador-orientador, o aluno une teoria e prática, ensino e pesquisa, adquirindo preparação adequada para sua futura ação profissional. Foi realizado um estudo de caso, descritivo, de abordagem quantitativa, onde buscamos identificar, no curso de graduação em Medicina da Universidade Estadual do Ceará, o perfil dos docentes que desenvolvem atividades de pesquisa integradas às didáticas. Para caracterizar esses profissionais foram utilizadas as variáveis: formação na graduação, ciclo em que lecionam as disciplinas e regimes de contratação. Concluímos que a participação em pesquisa é maior entre os docentes não médicos, que lecionam no ciclo básico e que possuem dedicação exclusiva. Acreditamos que a menor participação em pesquisa entre docentes médicos e que atuam no ciclo profissional decorra principalmente da alta proporção desses docentes com vinculação de apenas 20 horas à universidade. A contratação de professores com maiores vínculos e a inserção da pesquisa no currículo principal podem contribuir na formação em pesquisa e, portanto, aprimorar a formação de médicos críticos e reflexivos.

\section{ABSTRACT}

Research training is important for the preparation of physicians with a critical and reflective profile. Having the teacher as researcher-mentor, the student combines theory and practice, teaching and research, acquiring adequate preparation for their future professional activity. We conducted a descriptive case study, using a quantitative approach, in which we sought to identify the profile of teachers who combine research and learning activities at the Ceará State University School of Medicine. To characterize these professional the following variables were used: undergraduate education; cycle in which their disciplines are taught, and time dedication regime of employment. We concluded that research participation is higher among teachers: with non-medical degrees; who lecture in the basic cycle; and with exclusive dedication. We believe that the lower participation in research among medical and professional cycle teachers results mainly from the high proportion of these teachers with only 20 class hours at the university. Hiring teachers with greater time commitment and integrating research into the core curriculum are factors that could contribute toward improving research training and, therefore, the qualification of critical and analytically minded physicians. 


\section{INTRODUÇÃO}

A formação em pesquisa é um elemento importante para o preparo de um profissional crítico, reflexivo e consciente de seu papel social ${ }^{1}$. Desse modo, deve ser assumida como um importante componente curricular de cursos de graduação, que têm como preocupação formar profissionais capazes de atender as demandas de uma sociedade em constante transformação. Entendemos que a pesquisa, junto ao ensino e à extensão, merece a devida atenção dos formadores ao planejarem e desenvolverem ações que garantam o exercício dessa prática em contextos de formação na universidade.

O curso de graduação em Medicina da Universidade Estadual do Ceará (Uece) tem como objetivo formar médicos generalistas com capacidade analítica e poder criativo na aplicação dos conhecimentos e práticas adquiridos para a tomada de decisões, na promoção, manutenção e habilitação da saúde individual e coletiva, e na prevenção e tratamento dos agravos da saúde². Portanto, nesse âmbito, a pesquisa se configura um elemento basilar para a formação desses profissionais, sendo, em nosso entender, a mediadora de uma ação crítico-reflexiva, de médicos conscientes e participativos da realidade social em que estão inseridos e na qual atuam. Logo, concordamos com Demo ${ }^{3}$ na sua compreensão da pesquisa também como princípio educativo, segundo o qual o aluno, mediante a investigação, une teoria e prática como preparação adequada para sua futura ação profissional.

Apoiando este entendimento, Aguiar $^{4}$ (p. 306) relata que "está ficando indefensável não investir na pesquisa na escola médica", ressaltando a importância não apenas da "pesquisa na educação médica" - que tem o aluno como produtor do conhecimento e o docente como orientador -, mas também a "pesquisa sobre a educação médica" - , que, por meio da descrição de experiências, da elaboração teórica e da avaliação, dá suporte às transformações da formação médica no Brasil hoje, ressaltando, no entanto, que não é fácil articular a pesquisa ao ensino nos cursos de Medicina.

Em um estudo sobre Iniciação Científica (IC) na graduação de Medicina, Oliveira et al. ${ }^{5}$ (p. 312) acentuam que, entre as diversas causas para a não participação dos estudantes de Medicina em atividades de pesquisa, estão, em ordem crescente: "falta de interesse do aluno", "inexistência de pessoal qualificado ou motivado", "carência de condições materiais" e "falta de estímulo institucional para a realização de pesquisa". Tendo o foco principalmente na "pesquisa na educação médica" e na "inexistência de pessoal qualificado ou motivado", nosso estudo busca identificar a existência de perfis docentes mais associados a práticas de atividades de pesquisa, porquanto entendemos que a integração da pesquisa às atividades didáticas estimula o desenvolvimento da atitude investigativa dos alunos de graduação em Medicina, contribuindo para uma formação diferenciada.

\section{METODOLOGIA}

Trata-se de um estudo de caso, descritivo, de abordagem quantitativa. Neste trabalho, buscamos identificar, no colegiado do curso de graduação em Medicina da Universidade Estadual do Ceará, o perfil dos docentes/pesquisadores que potencialmente desenvolvem atividades de pesquisa integrada às atividades didáticas.

Para caracterizar o perfil dos profissionais desse colegiado, foram utilizadas as variáveis: (a) formação em nível de graduação (médicos ou não médicos); (b) ciclo no qual lecionam suas disciplinas (básico ou profissional); (c) seus regimes de trabalho (20 horas semanais, 40 horas semanais ou 40 horas semanais com dedicação exclusiva). Já para caracterizar as atividades de pesquisa na graduação, empregamos os parâmetros: (a) orientação de alunos de iniciação científica; (b) participação em grupos de pesquisa; (c) publicação de artigos em periódicos; (d) coordenação de projetos de pesquisa.

Dessa forma, nossa pesquisa iniciou-se com a obtenção, junto à Coordenação do curso, de uma listagem de todos os professores efetivos, discriminando as disciplinas ministradas (e, consequentemente, caracterizando o ciclo onde se insere cada disciplina), assim como o regime de trabalho de cada um deles.

Para identificar os docentes que orientam alunos de iniciação científica, consultamos o Processo de Seleção de Orientadores da Pró-Reitoria de Pós-Graduação e Pesquisa da Uece, dos semestres 2009.1, 2009.2, 2010.1 e 2010.26-9. Para identificar a participação em grupos de pesquisa da Uece, buscamos o Diretório de Grupos de Pesquisa ${ }^{10}$, considerando apenas os grupos certificados pela instituição de origem e atualizados nos últimos 12 meses. Por fim, para identificar a publicação de artigos em periódicos científicos, a coordenação de projetos de pesquisa e a formação em nível de graduação, consultamos os currículos dos professores disponíveis na Plataforma Lattes ${ }^{11}$, considerando artigos e projetos dos anos de 2009, 2010 e 2011.

Para contextualizar nossa discussão, apresentamos um breve histórico do curso, como também uma análise dos documentos normativos que o regem, focando nossa visão na importância conferida à pesquisa nesses textos.

Esta pesquisa faz parte do projeto "Pesquisa como princípio educativo: a gestão pedagógica dos saberes na docência universitária na área da saúde", aprovado pelo Comitê de Ética em Pesquisa da Uece, sob o Parecer nº 09503560-5.

\section{O CURSO DE MEDICINA DA UECE: BREVE HISTÓRICO}

O curso de graduação em Medicina da Universidade Estadual do Ceará é bastante jovem, tendo suas aulas iniciadas em 2003. 
A seleção dos alunos é feita por exame vestibular uma vez ao ano, de tal forma que as turmas são anuais, e não semestrais, como de costume na maioria das escolas médicas. Até o momento, formaram-se três turmas de jovens médicos pela Uece (em 2008, 2009 e 2010) ${ }^{12}$.

O curso de Medicina foi implementado em uma universidade com quase 30 anos de existência e que contava com vários cursos da área da saúde (entre eles: Enfermagem, Nutrição, Ciências Biológicas e Educação Física). Dessa forma, no que concernia às disciplinas básicas (Anatomia, Fisiologia, Saúde Coletiva, etc.), a instituição já contava com um corpo docente qualificado e infraestrutura laboratorial consolidada. Faltavam ainda, contudo, os profissionais médicos e os campos de prática profissional ${ }^{13}$

Segundo Silva ${ }^{13}$, o Governo do Estado do Ceará, mantenedor da Uece, já apresentava na época razoável infraestrutura hospitalar instalada na capital cearense e relutou em construir outro hospital de ensino para o recém-criado curso. A solução encontrada foi transformar, mediante uma Portaria do secretário da Saúde, os sete principais hospitais de referência do Governo do Estado em hospitais de ensino da Uece, servindo de campo de estágio supervisionado a todos os alunos do curso de Medicina ${ }^{14}$. Para aumentar a integração entre os profissionais médicos desses hospitais (vinculados à Secretaria Estadual de Saúde) e a própria Uece (mantida pela Secretaria Estadual de Ciência, Tecnologia e Educação Superior), foi criada a gratificação de "Professor de Práticas Médicas". Assim, a Coordenação do curso de Medicina da Uece poderia selecionar profissionais médicos que já fossem servidores públicos estaduais e que tivessem vínculo com a Secretaria Estadual de Saúde para que supervisionassem as atividades práticas dos alunos nesses hospitais de ensino, sem a necessidade de realizar novos concursos públicos e ensejar um vínculo permanente com a Uece ${ }^{15}$.

Paralelamente à "Portaria dos Hospitais-Escolas" e à "Lei do Professor de Práticas Médicas", concursos públicos foram ampliando paulatinamente o número de professores efetivos do curso de Medicina vinculados à Uece, preenchendo as lacunas especialmente nas disciplinas do ciclo profissional ${ }^{13}$. Logo, como são os professores efetivos que têm de fato vínculo permanente com a estrutura acadêmica da Uece e estão em contato mais próximo com os alunos, serão eles o foco do nosso estudo.

\section{A PESQUISA NOS DOCUMENTOS NORMATIVOS DA GRADUAÇÃO EM MEDICINA: RELEITURA DAS LINHAS E ENTRELINHAS}

De modo geral, dois documentos normatizam a criação e a condução de um curso superior: as Diretrizes Curriculares Nacionais (DCNs) e os projetos político-pedagógicos (PPPs).
As DCNs regem os cursos de graduação e servem como referência às instituições de ensino superior na elaboração de seus projetos político-pedagógicos. O PPP, por sua vez, revela objetivos, ações, características do processo educativo a ser por ele realizado e que serve como guia basilar do perfil de profissional que pretende formar. Iremos, pois, analisar brevemente como a pesquisa é tratada nos documentos normativos deste curso de Medicina.

A Resolução que institui as Diretrizes Curriculares Nacionais do Curso de Graduação em Medicina ${ }^{16}$, elaborada em 2001, manifesta desde o início a importância de as escolas médicas optarem pela formação de um perfil crítico e reflexivo de seus profissionais egressos (Art. $3^{\circ}$ ), além de darem importância ao desenvolvimento da capacidade de pensar criticamente sua realidade, da autonomia e discernimento para assegurar a qualidade da prestação de seus serviços (Art. $4^{\circ}$ ). É obscuro, entretanto, o papel que a pesquisa ou a relação ensino/pesquisa pode desempenhar na formação desse perfil entendido como crítico-reflexivo.

Compreendemos que o objetivo das DCNs é apontar as principais características que os cursos devem possuir, não cabendo especificar todo o seu currículo. Entendemos, porém, que o que for esquecido ou não enfatizado nos documentos normativos gerais tem uma tendência maior de ser igualmente omitido dos documentos específicos de cada curso, como veremos mais adiante.

No que diz respeito às competências e habilidades gerais e específicas necessárias à formação do médico, as DCNs ressaltam a importância do domínio da metodologia científica para filtrar as informações que chegam a ele e para a geração de conhecimentos (Art. $5^{\circ}$ ). Enfatizam ainda a necessidade do raciocínio crítico para a resolução de problemas clínicos e para a escolha das condutas terapêuticas mais adequadas (Art. $5^{\circ}$ ). Já os programas de iniciação científica, em que se verifica a possibilidade de este aluno vivenciar ativamente a relação entre teoria e prática em seu cotidiano, são encarados apenas como atividades complementares (Art. $8^{\circ}$ ).

Quanto à organização dos cursos e à elaboração de seus projetos político-pedagógicos, defende-se a necessidade de adotar estratégias didáticas que ponham o aluno no centro da aprendizagem com apoio do professor, caracterizado como facilitador e mediador deste processo. Defende-se, ainda, a ideia de que a participação do aluno deve ser ativa e integrada ao ensino, à pesquisa e à extensão/assistência (Art. $9^{\circ}$ ).

Logo, para as DCNs do curso de Medicina, a pesquisa e o domínio dos princípios científicos são encarados como ferramentas que permitem a formação de conhecimentos e a assimilação crítica das informações que o futuro profissional 
deve utilizar no dia a dia. Nesse documento, não está clara a necessidade da inserção da pesquisa no currículo principal, nem há o reconhecimento de sua imprescindibilidade para a formação de profissionais médicos crítico-reflexivos. Somente o Parecer ${ }^{17}$ (documento que orientou a formulação das DCNs) demonstra tentar enfatizar o papel da pesquisa na formação médica, privilegiando "a investigação como eixo integrador que retroalimenta a formação e a prática médica" (p. 13). Infelizmente, esta passagem foi suprimida do texto final da Resolução.

Diferentemente de boa parte das escolas médicas do País orientada a elaborar novos PPPs em consonância com as novas DCNs de Medicina, o curso da Uece já nasceu fortemente influenciado pelas diretrizes em vigor (uma vez que as DCNs foram elaboradas em 2001, e o projeto de criação do curso de Medicina foi preparado no ano seguinte). O reflexo desta influência pode ser constatado já no primeiro tópico do $\mathrm{PPP}^{2}$, denominado "Concepção, Finalidades e Objetivos", quando é afirmado:

O perfil delineado do médico egresso da instituição contempla: formação generalista, crítica e reflexiva [...] sendo capaz de pensar criticamente, de analisar os problemas da sociedade e de procurar soluções para os mesmos [...] avaliar, sistematizar e decidir as condutas mais adequadas, baseadas em evidências científicas [...] (p. 69-70)

Nos tópicos seguintes, tais como: "Missão" e "Objetivos do Curso", claras referências às DCNs são encontradas nas competências que o profissional egresso do curso deve ter, a exemplo do que afirmamos: "ter raciocínio crítico na interpretação dos dados" (p. 72) e "conhecer os princípios da metodologia científica" (p. 73).

Fortemente inspirado nas DCNs, o PPP do curso de Medicina da Uece também omite a pesquisa de seu currículo principal, embora percebamos uma tentativa de integrar a Iniciação Científica e outras atividades complementares ao currículo principal. O PPP afirma que tais atividades complementares - IC, monitorias, estágios, participação em eventos científicos, apresentação de trabalhos e publicação de artigos — devem "ser computadas com carga horária a figurar no histórico, observando os padrões e carga horária a ser estipulada pela Pró-Reitoria de Graduação da Uece" (p. 38). Infelizmente, este mecanismo de integração da Iniciação Científica com o currículo principal não é efetivado na prática em virtude de ser a grade curricular bastante rígida no curso. Logo, as atividades extracurriculares não são computadas na carga horária dos alunos, que, para colarem grau, necessitam passar por todas as disciplinas do curso (que são todas obrigatórias). Também não há disciplinas optativas neste curso de Medicina² .

Além da grade curricular deveras inflexível, percebemos nela uma nítida divisão entre as disciplinas que ocorrem nos dois primeiros anos e entre aquelas ocorrentes do terceiro ano da graduação em diante. No primeiro e segundo anos, os alunos passam por disciplinas das ciências básicas, que são comuns aos outros cursos da saúde, ministradas por professores de graduações diversas e que são sediadas principalmente em salas de aulas no campus da Uece. Já nos dois anos seguintes, ocorre o predomínio das disciplinas ofertadas somente por médicos, focadas principalmente nas especialidades médicas, ministradas geralmente em um dos hospitais de ensino. Os últimos dois anos são reservados ao internato. Dessa forma, a grade curricular do curso de Medicina da Uece reproduz a segregação entre os chamados ciclos básico e profissional, cuja origem é relatada por Lampert ${ }^{18}$ (p. 65):

[...] as escolas médicas no Brasil [...] a partir da Reforma Universitária de 1968 (Lei 5.540/68), passam a adotar oficialmente o modelo americano. [...] o ensino fica dividido em dois ciclos, um de disciplinas básicas - o ciclo básico - e outro de disciplinas ditas profissionalizantes. Chama-se a esse último "ciclo profissionalizante", porque corresponde às especialidades e ao estágio denominado Internato Curricular.

Pelo fato de reproduzir a segregação entre esses ciclos em sua grade curricular, o curso de Medicina da Uece nos obriga a levar em consideração estes conceitos para a caracterização dos perfis de seus docentes durante nossa investigação.

A análise das ementas das disciplinas voltadas à pesquisa é outra forma de avaliar como é encarada na prática a formação para a pesquisa no curso de Medicina. Com a colação de grau de sua primeira turma, houve pequena remodelação da grade curricular, ocorrendo algumas mudanças ínfimas na reorganização das disciplinas e deixando o curso com duas disciplinas de formação para a pesquisa: uma no primeiro semestre e outra no oitavo semestre (último semestre antes dos dois anos de internato). Assim, o curso adota uma estrutura muito semelhante à dos outros cursos de saúde da Uece, como demonstram Nóbrega-Therrien e Feitosa ${ }^{19}$ (p. 230), em uma pesquisa sobre os cursos da Saúde da Uece:

As disciplinas [dos cursos de saúde da Uece] estão divididas como introdutórias e conclusivas. [...] Notamos um caráter mais teórico para as primeiras, que se encarregam de fornecer aos alunos de graduação os elementos básicos da investigação [...]. Um caráter prioritaria- 
mente prático fica reservado para o segundo grupo das disciplinas [...] responsável pelo desenvolvimento, por parte dos alunos, do Projeto de Monografia [...].

Embora contribua para a formação em pesquisa dos alunos de Medicina, esta estrutura curricular apresenta uma série de problemas. Em especial, temos a grande lacuna temporal entre a disciplina introdutória e a disciplina de aplicação prática do trabalho científico, uma vez que é pouco provável que o aluno retenha por até três anos as informações obtidas no primeiro semestre sem que haja uma continuidade desses conteúdos ao longo do curso. Falta-nos também uma garantia de que esse processo de pesquisa será integrado às demais disciplinas do curso.

Portanto, a análise que empreendemos mostra que as DCNs de Medicina influenciaram fortemente o PPP do curso investigado, fato atribuído também ao intervalo de menos de um ano entre a elaboração dos dois documentos. Dito de outra forma, ambos não expressam a importância da pesquisa em seus currículos principais. O projeto político-pedagógico, por seu caráter mais prático, começa a dar sinais de tentativa de incorporação da Iniciação Científica ao currículo principal, embora ainda de modo bastante embrionário.

Pouco servem, contudo, documentos normativos que ressaltem a importância da formação em pesquisa se não houver um corpo docente devidamente qualificado para dar o suporte teórico-metodológico necessário à formação dos alunos. Para analisar este ponto, iniciaremos no tópico a seguir o estudo sobre o perfil do colegiado do curso de Medicina da Uece e sua relação com a pesquisa.

\section{RESULTADOS}

O curso de Medicina da Uece conta com 44 docentes efetivos vinculados ao seu colegiado. Considerando uma evasão de alunos ao longo do curso de apenas 3,5\% (resultado obtido nas três primeiras turmas, em que se formaram 116 dos 120 alunos iniciais), teríamos cerca de 230 alunos matriculados na graduação em Medicina, o que resultaria numa média de 5,3 alunos para cada docente efetivo. Ressaltamos que, antes de pensar em comparar as médias alunos/professor entre diferentes cursos ou universidades, é necessário dimensionar também a participação desses docentes em outros cursos de graduação ou em programas de pós-graduação, bem como considerar o regime de dedicação de cada docente, comparações estas que não são o foco deste trabalho.

Uma vez que parte significativa dos nossos dados seria coletada pela Plataforma Lattes do $\mathrm{CNPq}^{11}$, preocupamo-nos com um possível viés de informação em virtude de eventuais desatualizações dos currículos dos professores estudados. A Tabela 1 nos mostra, contudo, que em uma porcentagem acumulada, 36,4\% dos docentes atualizaram seus currículos nos últimos dois meses, 59,1\% nos últimos seis meses, e 72,7\% no último ano. Por outro lado, quatro $(9,1 \%)$ docentes não possuem Currículo Lattes. Considerando a imprescindibilidade deste currículo para a pesquisa acadêmica - uma vez que ele é exigido para a institucionalização da pesquisa na universidade, para solicitação de financiamento por agências de fomento, para aprovação de projetos de pesquisa em comitês de ética, etc. - , consideramos estes docentes sem Currículo Lattes como também sem atividade em pesquisa, o que foi compatível com o fato de eles também não orientarem bolsistas de IC (dados obtidos por meio de outra fonte, ou seja, em documentos da Pró-Reitoria de Pós-Graduação e Pesquisa da Uece).

TABELA 1

Atualização dos Currículos Lattes dos professores, em frequências e porcentagens simples e acumuladas (Curso de Medicina da UECE, abril de 2011)

\begin{tabular}{lrrrc}
\hline $\begin{array}{c}\text { Última atualização do Currículo } \\
\text { Lattes ocorrida em: }\end{array}$ & $\mathbf{n}$ & $\mathbf{f ( \% )}$ & $\mathbf{~ N}$ & $\mathbf{F ~ ( \% )}$ \\
\hline Até 2 meses atrás & 16 & $36,4 \%$ & 16 & $36,4 \%$ \\
Entre 2 e 6 meses atrás & 10 & $22,7 \%$ & 26 & $59,1 \%$ \\
Entre 6 e 12 meses atrás & 6 & $13,6 \%$ & 32 & $72,7 \%$ \\
Entre 12 e 24 meses atrás & 4 & $9,1 \%$ & 36 & $81,8 \%$ \\
Mais de 24 meses atrás & 4 & $9,1 \%$ & 40 & $90,9 \%$ \\
Sem CV Lattes & 4 & $9,1 \%$ & 44 & $100, \%$ \\
Total & 44 & $100 \%$ & - & - \\
\hline
\end{tabular}

Fonte: Plataforma Lattes do CNPq.

A Tabela 2 sintetiza a participação docente nas diferentes atividades de pesquisa por tipo de graduação, pelo ciclo no qual cada docente leciona prioritariamente e por tipo de regime de trabalho dos professores.

Ao analisarmos a formação no plano da graduação dos 44 docentes efetivos, encontramos $29(65,9 \%)$ docentes formados em Medicina e 15 (34,1\%) formados em outro curso de graduação. Apenas um dos docentes possuía título de graduado tanto em Medicina como em outro curso, porém, como suas atividades docentes estavam ligadas primordialmente a sua formação médica, optamos por classificá-lo na categoria de "médico".

Já no que se refere ao ciclo onde cada docente leciona prioritariamente, classificamos 19 (43,2\%) docentes como ministrando aulas especialmente no ciclo profissional e $25(56,8 \%)$ 
TABELA 2

Participação docente em atividades de pesquisa por graduação, ciclo e regime (Curso de Medicina da UECE, abril de 2011)

\begin{tabular}{|c|c|c|c|c|c|c|c|c|c|c|c|c|c|c|c|c|c|c|}
\hline \multirow{3}{*}{ Docentes } & \multicolumn{4}{|c|}{$\begin{array}{c}\text { Participação em Grupos } \\
\text { de Pesquisa }\end{array}$} & \multicolumn{4}{|c|}{$\begin{array}{l}\text { Orientação de Alunos de } \\
\text { Iniciação Científica }{ }^{2}\end{array}$} & \multicolumn{4}{|c|}{$\begin{array}{c}\text { Publicação de Artigos } \\
\text { em Periódicos }\end{array}$} & \multicolumn{4}{|c|}{$\begin{array}{c}\text { Coordenação de Projetos } \\
\text { de Pesquisa }\end{array}$} & \multicolumn{2}{|c|}{ Total } \\
\hline & \multicolumn{2}{|c|}{ SIM } & \multicolumn{2}{|c|}{ NÃO } & \multicolumn{2}{|c|}{ SIM } & \multicolumn{2}{|c|}{ NÃO } & \multicolumn{2}{|c|}{ SIM } & \multicolumn{2}{|c|}{ NÃO } & \multicolumn{2}{|c|}{ SIM } & \multicolumn{2}{|c|}{ NÃO } & \multirow[b]{2}{*}{$\mathbf{n}$} & \multirow[b]{2}{*}{$f(\%)$} \\
\hline & $\mathrm{n}$ & $f(\%)$ & $\mathrm{n}$ & $f(\%)$ & $\mathbf{n}$ & $f(\%)$ & $\mathrm{n}$ & $f(\%)$ & $\mathrm{n}$ & $f(\%)$ & $\mathbf{n}$ & $f(\%)$ & $\mathbf{n}$ & $f(\%)$ & $\mathrm{n}$ & $f(\%)$ & & \\
\hline \multicolumn{19}{|l|}{ Graduação } \\
\hline Médicos & 6 & $20,7 \%$ & 23 & $79,3 \%$ & 8 & $27,6 \%$ & 21 & $72,4 \%$ & 14 & $48,3 \%$ & 15 & $51,7 \%$ & 8 & $27,6 \%$ & 21 & $72,4 \%$ & 29 & $65,9 \%$ \\
\hline Não médicos & 11 & $73,3 \%$ & 4 & $26,7 \%$ & 10 & $66,7 \%$ & 5 & $33,3 \%$ & 10 & $66,7 \%$ & 5 & $33,3 \%$ & 7 & $46,7 \%$ & 8 & $53,3 \%$ & 15 & $34,1 \%$ \\
\hline \multicolumn{19}{|l|}{ Ciclo: } \\
\hline Profissional & 1 & $5,3 \%$ & 18 & $94,7 \%$ & 3 & $15,8 \%$ & 16 & $84,2 \%$ & 8 & $42,1 \%$ & 11 & $57,9 \%$ & 4 & $21,1 \%$ & 15 & $78,9 \%$ & 19 & $43,2 \%$ \\
\hline Básico & 16 & $64,0 \%$ & 9 & $36,0 \%$ & 15 & $60,0 \%$ & 10 & $40,0 \%$ & 16 & $64,0 \%$ & 9 & $36,0 \%$ & 11 & $44,0 \%$ & 14 & $56,0 \%$ & 25 & $56,8 \%$ \\
\hline \multicolumn{19}{|l|}{ Regime: } \\
\hline $20 \mathrm{~h}$ & 0 & $0,0 \%$ & 16 & $100,0 \%$ & 2 & $12,5 \%$ & 14 & $87,5 \%$ & 6 & $37,5 \%$ & 10 & $62,5 \%$ & 4 & $25,0 \%$ & 12 & $75,0 \%$ & 16 & $36,4 \%$ \\
\hline $40 \mathrm{~h}$ & 6 & $50,0 \%$ & 6 & $50,0 \%$ & 5 & $41,7 \%$ & 7 & $58,3 \%$ & 5 & $41,7 \%$ & 7 & $58,3 \%$ & 4 & $33,3 \%$ & 8 & $66,7 \%$ & 12 & $27,3 \%$ \\
\hline $\mathrm{DE}$ & 11 & $68,8 \%$ & 5 & $31,3 \%$ & 11 & $68,8 \%$ & 5 & $31,3 \%$ & 13 & $81,3 \%$ & 3 & $18,8 \%$ & 7 & $43,8 \%$ & 9 & $56,3 \%$ & 16 & $36,4 \%$ \\
\hline Total & 17 & 38,6 & 27 & $61,4 \%$ & 18 & $40,9 \%$ & 26 & $59,1 \%$ & 24 & $54,5 \%$ & 20 & $45,5 \%$ & 15 & $34,1 \%$ & 29 & $65,9 \%$ & 44 & $100,0 \%$ \\
\hline
\end{tabular}

Fontes:

1 - Diretório de Grupos de Pesquisa do CNPq.

2 - Pró-Reitoria de Pós-Graduação e Pesquisa da UECE.

3 - Plataforma Lattes do CNPq.

docentes como lecionando principalmente no ciclo básico. Ressalta-se que vários professores lecionavam disciplinas em ambos os ciclos. Nestes casos, optamos por classificar cada professor no ciclo da disciplina com o maior número de créditos ou no ciclo da disciplina da qual ele fosse o coordenador. A adoção destes dois critérios foi suficiente para evitar dubiedades nesta classificação. Lembramos também que nesta pesquisa não estamos estudando os "professores de práticas médicas", que, embora lecionem nas disciplinas do ciclo profissional, não têm vinculação direta com a universidade.

Por fim, em relação ao regime de trabalho, identificamos $16(36,4 \%)$ docentes que possuem contratos de 20 horas se- manais, $12(27,3 \%)$ com contratos de 40 horas semanais sem dedicação exclusiva e $16(36,4 \%)$ professores contratados com dedicação exclusiva. Embora não estivesse em nosso foco inicial, durante a consolidação dos dados, identificamos alguns padrões que julgamos pertinente aprofundar. Primeiramente, encontramos certo predomínio do regime de 20 horas semanais entre médicos e entre professores do ciclo profissional, enquanto entre profissionais não médicos e do ciclo básico ocorria o oposto, com predomínio do regime de dedicação exclusiva. Desta forma, elaboramos o Gráfico 1, que relaciona os regimes de trabalho à formação em nível de graduação e aos ciclos em que as disciplinas são lecionadas.

\section{GRÁFICO 1}

Caracterização dos docentes de cada regime de trabalho, por graduação e por ciclo onde leciona

(Curso de Medicina da UECE, abril de 2011)

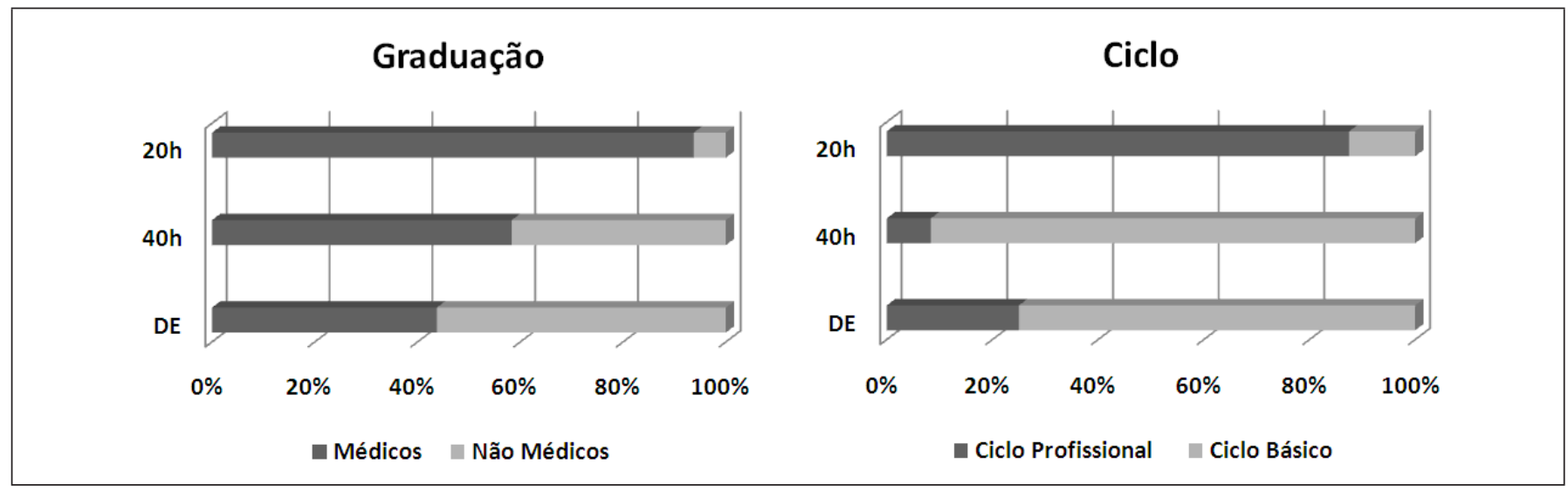




\section{TABELa 3}

Caracterização dos docentes "muito ativos" e "inativos" em pesquisa, segundo graduação, ciclo onde leciona e regime de trabalho (Curso de Medicina da UECE, abril de 2011)

\begin{tabular}{|c|c|c|c|c|c|c|c|c|c|c|c|c|c|c|c|}
\hline \multirow{3}{*}{ Docentes } & \multicolumn{4}{|c|}{ Graduação } & \multicolumn{4}{|c|}{ Ciclo } & \multicolumn{6}{|c|}{ Regime } & \multirow{3}{*}{$\begin{array}{c}\text { Total } \\
\mathbf{n}\end{array}$} \\
\hline & \multicolumn{2}{|c|}{ Médicos } & \multicolumn{2}{|c|}{ Não Médicos } & \multicolumn{2}{|c|}{ Básico } & \multicolumn{2}{|c|}{ Profissional } & \multicolumn{2}{|c|}{$20 \mathrm{~h}$} & \multicolumn{2}{|c|}{$40 \mathrm{~h}$} & \multicolumn{2}{|c|}{ DE } & \\
\hline & $\mathrm{n}$ & $f(\%)$ & $\mathrm{n}$ & $f(\%)$ & $\mathrm{n}$ & $f(\%)$ & $\mathrm{n}$ & $f(\%)$ & $\mathrm{n}$ & $f(\%)$ & $\mathrm{n}$ & $f(\%)$ & $\mathrm{n}$ & $f(\%)$ & \\
\hline Ativos em pesquisa & 4 & $36,4 \%$ & 7 & $63,6 \%$ & 10 & $90,9 \%$ & 1 & $9,1 \%$ & 0 & $0,0 \%$ & 4 & $36,4 \%$ & 7 & $63,6 \%$ & 11 \\
\hline Inativos em pesquisa & 13 & $76,5 \%$ & 4 & $23,5 \%$ & 7 & $41,2 \%$ & 10 & $58,8 \%$ & 9 & $52,9 \%$ & 6 & $35,3 \%$ & 2 & $11,8 \%$ & 17 \\
\hline
\end{tabular}

Posteriormente, também foi observada a existência de dois perfis opostos no colegiado deste curso de Medicina: professores bastante ativos em pesquisa, que desenvolviam as quatro atividades de pesquisa avaliadas em nosso estudo; e professores inativos em pesquisa, que não apresentaram nenhuma atividade de pesquisa entre as quatro avaliadas. Preparamos, então, a Tabela 3, que sintetiza a caracterização em termos de regime, graduação e ciclo dos professores "muito ativos" e "inativos" em pesquisa.

\section{DISCUSSÃO}

Analisando a participação em atividades de pesquisa dos docentes do curso de Medicina da Uece (Tabela 2), separando-os de acordo com suas formações na graduação, observamos que a participação em pesquisa é maior entre os profissionais não médicos do que entre os profissionais formados em Medicina. Percebemos que, nos parâmetros "publicação de artigos em periódicos" e "coordenação de projetos de pesquisa", a diferença entre médicos e não médicos se torna menor, apenas 18,4 e 19,1 pontos percentuais (pp), respectivamente.

Quando passamos a avaliar os parâmetros de atividades de pesquisa em relação ao ciclo em que os docentes lecionam, encontramos maior participação dos professores do ciclo básico em relação aos do ciclo profissional em todos os parâmetros avaliados. Destacamos, porém, que a diferença entre a participação entre os docentes desses dois ciclos se torna maior do que a diferença entre não médicos e médicos. Mais uma vez, encontramos nos parâmetros "publicação de artigos em periódicos" e "coordenação de projetos de pesquisa" as menores diferenças de participação (21,9 e 22,9 pp, respectivamente).

Assim, mediante a análise dessas duas primeiras variáveis, percebemos que os alunos de graduação deste curso de Medicina possuem boas oportunidades de se integrar a atividades de pesquisa com seus professores do ciclo básico, formados por profissionais das mais diversas graduações (não apenas Medicina, mas, também, Farmácia, Biologia, Enfermagem, etc.). Estas pesquisas provavelmente se concentrariam nas ciências básicas da saúde (Morfologia, Fisiologia, Patologia, Saúde Coletiva, etc.), que são de enorme importância para a formação de profissionais de saúde. Estes mesmos estudantes, contudo, provavelmente terão poucas oportunidades de desenvolver atividades de pesquisa relacionadas diretamente com o exercício da Medicina, uma vez que, entre professores médicos e do ciclo profissional, são baixíssimas as taxas de "participação em grupos de pesquisa" e de "orientação de alunos de Iniciação Científica". O fato de estes docentes apresentarem melhores indicadores de participação em "publicação de artigos em periódicos" e "coordenação de projetos de pesquisa" pode ser resultado do desenvolvimento de outras atividades de pesquisa não relacionadas diretamente a sua docência na Uece (como, por exemplo, publicação em periódicos de relatos de casos, coordenação de projetos de pesquisa em outros hospitais que não os utilizados pela Uece, publicação de trabalhos oriundos de suas pós-graduações em outras instituições, etc.), sendo necessário um estudo posterior para identificar suas reais causas.

Já em relação ao regime de trabalho dos professores, os dados demonstram o que já era esperado, isto é, que os professores possuidores de maiores vínculos com a universidade possuem também maior participação em pesquisa, ou seja, docentes com dedicação exclusiva (DE) atuam mais em pesquisa do que docentes de 40 horas semanais, e estes, por sua vez, pesquisam mais do que professores de apenas 20 horas semanais. Esse padrão foi observado nos quatro tipos de atividade de pesquisa avaliados. Chama-nos a atenção a total falta de participação de "docentes 20 h" em grupos de pesquisa e, por outro lado, a alta porcentagem de "docentes DE" com publicação de artigos em periódicos no período avaliado.

Como demonstrado no Gráfico 1, entre os profissionais de 20 horas predominam profissionais médicos e docentes do ciclo profissional. Já entre os professores de 40 horas e DE, embora haja certo equilíbrio entre a proporção de médicos e de não médicos, ocorre clara predominância de profissionais do ciclo básico em detrimento dos docentes do ciclo profissional. 
Uma vez que o maior vínculo com a universidade está claramente ligado à maior participação em atividades de pesquisa, acreditamos que a não participação de médicos do ciclo profissional em atividades de pesquisa decorra, em parte, de seus menores vínculos com a Uece.

Dessa forma, poderíamos apontar a necessidade de priorizar a contratação de profissionais com maior vínculo com a universidade, preferencialmente sob o regime de dedicação exclusiva. Profissionais de 20 horas têm sua carga horária preenchida quase exclusivamente pelas atividades didáticas. Embora o ensino tenha sido a razão primeira da existência das universidades e das escolas médicas, todas elas devem ser pautadas no tripé ensino-pesquisa-extensão/assistência. Sabemos, no entanto, das dificuldades de contratar professores sob o regime de dedicação exclusiva. Além do maior custo financeiro para o pagamento da folha salarial por parte das instituições, no caso dos cursos de Medicina ainda encontramos resistência dos profissionais médicos em abdicar de outros vínculos empregatícios, que resultam quase sempre em uma remuneração financeira maior do que a de professor universitário, fatores que inviabilizam o desenvolvimento da cultura acadêmica por parte destes docentes inseridos no curso da Uece.

A análise da Tabela 3 evidencia que mais da metade dos "inativos em pesquisa" se encontra predominantemente nos regimes de 20 horas (52,9\%) e em menor escala no regime de 40 horas (35,3\%). Essa mesma tabela também nos mostra, contudo, a existência de dois profissionais sob o regime de dedicação exclusiva que não se dedicam a atividades de pesquisa. Tal peculiaridade talvez seja explicada pela análise que fizemos dos documentos normativos do curso, que não situam de forma clara o papel central que a pesquisa deve ter na graduação em Medicina, permitindo que até mesmo profissionais sob o regime de dedicação exclusiva tenham a "regalia" de poder não ocupar pelo menos parte de sua carga horária com pesquisa.

Por fim, estas análises nos remetem ao que consideramos o perfil ideal, ou seja, o dos docentes "muito ativos" em pesquisa. Percebemos a incompatibilidade entre esse perfil e um vínculo em regime de apenas 20 horas semanais. Além do predomínio dos regimes de 40 horas e DE, notamos também que praticamente todos os docentes com este perfil almejado (90,9\%) lecionam suas disciplinas no ciclo básico, o que reforça nossa preocupação quanto à inexistência de docentes "muito ativos" em pesquisa atuando no ciclo profissional.

\section{CONSIDERAÇÕES FINAIS}

Concluímos que a participação em pesquisa é maior entre os profissionais não médicos, entre professores do ciclo básico e entre os profissionais com dedicação exclusiva. As maiores diferenças de participação em pesquisa ocorrem entre profissionais de 20 horas e DE, enquanto as menores diferenças ocorrem entre médicos e não médicos.

Acreditamos que a menor participação em pesquisa entre profissionais médicos e que atuam no ciclo profissional se dá pela alta proporção de professores vinculados com apenas 20 horas. A participação em atividades de pesquisa por parte dos profissionais com esse perfil poderia ter outro agravante, uma vez que tenderia a ser ainda menor se incluíssemos nos estudos os professores de práticas médicas - médicos que lecionam no ciclo profissional, mas não têm vínculo direto com a universidade e que provavelmente teriam sérias dificuldades de realizar atividades de pesquisa com seus alunos sem poder contar com a estrutura e a cultura da academia. Estudos posteriores são importantes para avaliar como ocorre, de fato, a integração entre ensino e pesquisa pelos professores de práticas médicas.

A contratação de mais professores com vínculo de dedicação exclusiva ou mesmo 40 horas, assim como a geração e manutenção de um vínculo maior dos professores de práticas médicas à Uece nos parecem opções para aumentar a integração entre ensino e pesquisa neste curso de Medicina, em especial nos conteúdos especificamente médicos, relacionados ao ciclo profissional. Para percorrer este caminho, é necessário, além de ultrapassar inúmeros obstáculos estruturais, sociais e financeiros, modificar a compreensão do próprio colegiado do curso, ressaltando que a opção por abertura de concursos com carga horária mínima (20 horas) produz reflexos diretos e indiretos no desenvolvimento da pesquisa, na geração da cultura acadêmica e, consequentemente, na formação do profissional médico.

Não menos importante é a necessidade de modificar radicalmente a grade curricular deste curso. Embora o seu PPP tenha sido elaborado recentemente, sendo bastante influenciado pelas novas DCNs, sua grade curricular reproduz uma segregação excessiva entre os ciclos básico e profissional. A substituição de disciplinas por módulos longitudinais que integram os conhecimentos das ciências básicas aos conteúdos específicos da Medicina está sendo utilizada com sucesso em várias escolas médicas pelo País. Além disso, é necessário reduzir a quantidade de disciplinas obrigatórias, criar disciplinas optativas de acordo com os interesses dos alunos e garantir que atividades "extracurriculares", especialmente as de pesquisa, sejam computadas na carga horária oficial de cada aluno.

Acreditamos que a pesquisa pode desempenhar um papel importante na formação de futuros médicos críticos e reflexivos, capazes de responder às novas demandas sociais. Para que isto ocorra, no entanto, é necessário inserir as atividades 
de pesquisa no currículo principal dos cursos de graduação por meio de professores que as vivenciem cotidianamente também em sala de aula, proporcionando a seus alunos uma formação diferenciada.

\section{AGRADECIMENTOS}

Agradecemos ao Conselho Nacional de Desenvolvimento Científico e Tecnológico (CNPq), à Fundação Cearense de Apoio ao Desenvolvimento Científico e Tecnológico (Funcap), à Coordenação de Aperfeiçoamento de Pessoal de Nível Superior (Capes) e à Pró-Reitoria de Pós-Graduação e Pesquisa da Universidade Estadual do Ceará (PROPGPq-Uece) pela concessão de bolsas de Iniciação Científica e de Demanda Social.

\section{REFERÊNCIAS}

1. Schön D. Educando o profissional reflexivo: um novo design para o ensino e a aprendizagem. Porto Alegre: Artes Médicas; 2000.

2. Universidade Estadual do Ceará. Centro de Ciências da Saúde. Proposta de Reconhecimento do Curso de Medicina. Projeto Político-Pedagógico. Fortaleza:UEC; 2006.

3. Demo P. Pesquisa: princípio científico e educativo. $6^{\underline{a}}$ ed. São Paulo: Cortez; 1999.

4. Aguiar AC. A pesquisa e a educação médica no Brasil hoje: reflexões sobre metodologia e estratégias. In: Marins JJN, Rego S, Lampert JB, Araujo JGC, org. Educação médica em transformação: instrumentos para a construção de novas realidades. São Paulo: Hucitec; 2004. p.304-324.

5. Oliveira NA, Alves LA, Luz MR. Iniciação científica na graduação: o que diz o estudante de medicina?. Rev Bras Educ Med. 2008;32(3)309-14.

6. Universidade Estadual do Ceará. Pró-Reitoria de Pós-Graduação e Pesquisa. Núcleo de Pesquisa. Processo de Seleção de Orientadores 2009-2010: relatório final PIBIC/ CNPq, IC/UECE e PROVIC/UECE. Fortaleza:UEC; 9 jul. 2009.

7. Universidade Estadual do Ceará. Pró-Reitoria de Pós-Graduação e Pesquisa. Núcleo de Pesquisa. Processo de Seleção de Orientadores 2009-2: relatório ICT/FUNCAP (chamada pública 01/2009) e IC/UECE (chamada pública 02/2009). Fortaleza: UEC; 16 mar. 2010.

8. Universidade Estadual do Ceará. Pró-Reitoria de Pós-Graduação e Pesquisa. Núcleo de Pesquisa. Processo de Seleção de Orientadores 2010-1: relatório PIBIC/CNPq (chamada pública 02/2010) e PROVIC/UECE (chamada pública 03/2010). Fortaleza: UEC; 19 jul. 2010.

9. Universidade Estadual do Ceará Pró-Reitoria de Pós-Graduação e Pesquisa. Núcleo de Pesquisa. Processo de
Seleção de Orientadores 2010-2: relatório ICT/FUNCAP (chamada pública 21/2010) e IC/UECE (chamada pública 22/2010). Fortaleza: UCE; 10 fev. 2011.

10. Conselho Nacional de Desenvolvimento Científico e Tecnológico [homepage]. Diretório de Grupos de Pesquisa. [acesso em abr. 2011]. Disponível em: <http://dgp.cnpq. $\mathrm{br} /$ buscaoperacional>.

11. Conselho Nacional de Desenvolvimento Científico e Tecnológico [homepage]. Plataforma Lattes. [acesso em abr. 2011]. Disponível em: <http:/ / lattes.cnpq.br>.

12. Governo do Estado do Ceará [homepage]. Fortaleza: Governo do Estado do Ceará; c2011 - [acesso em 26 maio 2011]. Notícias. UECE forma mais uma turma do curso de Medicina. Notícias; [cerca de 1 tela]. Disponível em: http:/ / www.uece.br/uece/index.php/lista-de-noticias/1428-uece-forma-mais-uma-turma-do-curso-de-medicina.

13. Silva MGC. Curso de Medicina da UECE: concepção, criação e implantação (2002-2008). Fortaleza: Ed. UECE; 2009.

14. Ceará (Estado). Secretaria da Saúde. Portaria n⿳ำ 1218, de 06 de junho de 2003. Institui Comissão de técnicos da Secretaria da Saúde do Estado do Ceará — SESA. Diário Oficial do Estado do Ceará. Fortaleza, 04 ago. 2003. Seção 2, ano VI, n.146, p.29.

15. Ceará (Estado). Lei no 14.358 , de 19 de maio de 2009. Institui a Gratificação de Ensino de Práticas Médicas e Dá Outras Providências. Diário Oficial do Estado do Ceará. Fortaleza, 25 maio 2009. p.1-2.

16. Brasil. Ministério da Educação. Conselho Nacional de Educação. Câmara de Educação Superior. Resolução CNE/CES no 4 de 7 de novembro de 2001. Institui as Diretrizes Curriculares Nacionais do Curso de Graduação em Medicina. Diário Oficial da União, Brasília, 9 de novembro de 2001. Seção 1, p. 38.

17. Brasil. Ministério da Educação. Conselho Nacional de Educação. Câmara de Educação Superior. Parecer CNE/ CES no 1133 de 7 de agosto de 2001. Institui Diretrizes Curriculares Nacionais dos Cursos de Graduação em Enfermagem, Medicina e Nutrição. Diário Oficial da União. Brasília, 3 out. 2001. Seção 1E, p. 131.

18. Lampert JB. Tendências de mudanças na formação médica no Brasil: tipologia das escolas. São Paulo: Hucitec; 2002.

19. Nóbrega-Therrien SM, Feitosa LM. Ação Formativa e o Desafio para a Graduação em Saúde. Rev Bras Educ Méd. 2010;34(2)227-37.

\section{CONTRIBUIÇÃO DOS AUTORES}

Pedro Mansueto Melo Souza contribuiu na concepção e desenho do estudo, aquisição e análise dos dados, redação inicial e 
final do texto. Camila Almada Nunes e Clarice Santiago Silveira contribuíram na aquisição e análise dos dados, elaboração da versão inicial do artigo. Silvia Maria Nóbrega - Therrien contribuiu na concepção e desenho do estudo, revisão crítica para conteúdo intelectual significativo do artigo.
CONFLITO DE INTERESSES

Declarou não haver.

\section{ENDEREÇO PARA CORRESPONDÊNCIA}

Pedro Mansueto Melo Souza

Laboratório de Educação e Saúde Coletiva — Uece

Av. Paranjana, 1700

Itapery - Fortaleza

CEP 60740-000 - CE

E-mail: pedro.mansueto.m.s@gmail.com 